\title{
Landscape ecology and climate change adaptation: new perspectives in managing the change
}

\author{
Burghard C. Meyer $\cdot$ Sven Rannow
}

Received: 18 June 2013/Accepted: 22 June 2013/Published online: 13 July 2013

(C) Springer-Verlag Berlin Heidelberg 2013

\section{New perspectives in managing the change}

Managing climate change is considered one of the biggest challenges of the decades to come. Understanding its complex interaction with abiotic, biotic, and socioeconomic systems, as well as its effects on land use, landscapes, or even ecosystem services is an essential basis for the development of effective and efficient adaptation strategies. Landscape ecology is considered one of the disciplines that can provide essential insights into these interactions. The analysis of pattern and processes on landscape level must include assessment methods for existing trends as well as modelling of complex reactions in environmental, social, and economic systems. It can provide essential insight in the links between nature and society and derive the scientific and applied input for the adaptation to climate change. Both gradual as well as abrupt changes will affect landscapes and the services they provide for society. These effects are not only limited to direct changes of climate conditions but will also include indirect effects like changes in hydrological cycles or land use related management.

Successful adaptation and management, therefore, needs to be geared towards the maintenance of environmental integrity, the protection against unwanted or even

\section{B. C. Meyer $(\square)$}

Institute of Geography, University of Leipzig, Johannisallee 19a, 04103 Leipzig, Germany e-mail: burghard.meyer@olanis.de;

burghard.meyer@uni-leipzig.de

\section{S. Rannow}

Leibniz Institute of Ecological Urban and Regional

Development, 01217 Dresden, Germany

e-mail: s.rannow@ioer.de hazardous processes, and the exploitation of beneficial opportunities in response to actual or expected change. Knowledge from landscape ecology can help to guide the process of management from a static equilibrium view to a more adaptive actors- and participation-oriented approach.

Two symposia were held at the 8.IALE World Congress from 18 to 23 August 2011 in Beijing, China, to strengthen the transfer of knowledge from landscape ecology into adaptation planning. This special Issue is covering selected contributions from the symposia "Climate Change Adaptation-New perspectives in managing change in landscape ecology" and "Climate optimized land use-a sustainability strategy between adaption to and mitigation of climate change".

At the symposia, principles for adaptation to and managing of change were discussed, and it was realised that there is still some ground to cover before common general guidelines can be formulated. In the two mentioned symposia, investigations about key aspects of climate change adaptation in landscape systems were presented. They illustrate some of the current research activities in relation to (1) the investigation of greenhouse gas emissions and carbon sequestration problems in the context of landscape and land uses, (2) the development of new methods and models to investigate potential impacts, (3) the assessment of climate change impacts including scenario approaches, and (4) the identification of adequate response options for landscape management.

Investigation of greenhouse gas emissions and carbon sequestration problems in the context of landscape and land uses

There is an obvious overlap between the analysis of greenhouse gas (GHG) emissions and carbon sequestration 
in the context of land use systems and management options for landscape or land use systems in practice. Land use and land management changes are key drivers of GHG-emissions (e.g. by bio-energy crops, grassland management, drainage managements, or management of peat lands). They initiate changes in land cover and influence carbon dioxide and methane emissions as well as many other factors of the landscape balance and household. Plant, soil, and water balances have considerable leverage effects for the limitation of GHG in the atmosphere. However, the question remains how these aspects of mitigation can be included in adapted landscape management and which measures are adequate and feasible (e.g. incentives, $\mathrm{CO}_{2^{-}}$ compensation schemes, regulations and restriction for specified land uses, agro-environmental schemes, etc). Järveoja et al. (2012) and Saathoff et al. (2012) are discussing first answers in this regard.

Development of methods and models

There is a multitude of assessment approaches and related methods for climate impact analysis. Most methods are developed for specific purposes. Both basic and applied research is working hard to link the different components of landscape systems (e.g. the economic, social, and environmental perspectives). Different records or indicators are used including actual, historic, static, and dynamic aspects of observation. However, the need for cross-sectoral and integrated methods still persists. Landscape model systems are challenged by the fact that more complex methods will have a higher need for scientific verification and validation.

Another key aspect is the relevance of methods and models for decision-making. The contributions of Tao et al. (2012), Harrison et al. (2012), Li et al. (2012), and Rannow (2013) are illustrating different ways to include results in planning processes and decision-making.

\section{Assessment of climate change impacts}

There are multiple investigations and analysis of individual problems induced by changes in climate (e.g. chilling damage; droughts; floods; heat stress; effects on protected species). Further investigation and development of integrated assessments are needed to analyse the effect on local and socio-ecological resilience. A prerequisite for results that are relevant for decision-making is the reflection of management issues. It will be essential to strengthen the focus and link to main issues like spatial planning, GHGmitigation, food security, water management, hazards prevention, or conservation of biodiversity. Landscape ecology has to focus both on natural and cultural landscapes. This must also include urban systems. Climate change investigations in landscape ecology should elucidate new relationship among pattern, process, and scale of impacts. Gradual (slow) and abrupt change should be explored to provide solutions for adaptation measures. Expert systems and investigations on multiple impacts can help to develop applicable knowledge in the mentioned field of practice as shown by the contributions of Mezösi et al. (2012), Tao et al. (2012), and Li et al. (2012) in this issue.

Identification of adequate response options for landscape management

Landscape ecology has the potential to transfer the knowledge about impacts in concrete measures to solve the related problems. Successful adaptation to climate change will build on general considerations and principles; however, they need to be translated and specified to provide applicable and efficient response options. Adequate management options have to be identified. They will differ according to scale. In food production, for instance, measures can address national policies in relation to agroenvironmental measures as well as projects and economic activities on the level of individual farms or even parcels.

Up to now only few ideas and measures are applied and tested on the landscape level. Innovation and new scientific perspectives are asked in order to better understand the effects of new measures on different landscape functions and services. In addition, evaluation methods are needed to measure the success of adaptation activities and to compare the trade-offs between different adaptation options (e.g. hard and soft flood protection). First approaches are illustrated by Harrison et al. (2012), Li et al. (2012), Rannow (2013), and Saathoff et al. (2012).

The contributions and discussions of the symposia showed that landscape ecology can support climate change adaptation. They closed with the call to focus research activities on: (1) the impact of climate and climate change on land use, (2) the temporal and spatial changes of landscapes, (3) the assessment of sensitivity and vulnerability of landscapes, (4) the adaptive capacity of landscapes and their social systems as one of the often neglected factors, (5) the interrelationships between decision-making, uncertainty, and barriers of adaptation, (6) the impact of scale for investigations, the intrinsic complexity of each scale level and potential transfer functions between scales, (7) the use of statistical methods and models to analyse the relationship among pattern, process, and scale, and finally, (8) the resilience of landscapes as socio-ecological systems. 


\section{References}

Harrison PA, Holman IP, Cojocaru G, Kok K, Kontogianni A, Metzger MJ, Gramberger M (2012) Combining qualitative and quantitative understanding for exploring cross-sectoral climate change impacts, adaptation and vulnerability in Europe. Reg Environ Change. doi:10.1007/s10113-012-0361-y

Järveoja J, Laht J, Maddison M, Soosaar K, Ostonen I, Mander Ü (2012) Mitigation of greenhouse gas emissions from an abandoned Baltic peat extraction area by growing reed canary grass: life-cycle assessment. Reg Environ Change. doi:10.1007/s 10113-012-0355-9

Li X, Tian H, Wang Y, Li R, Song Z, Zhang F, Xu M, Li D (2012) Vulnerability of 208 endemic or endangered species in China to the effects of climate change. Reg Environ Change. doi: 10.1007/s10113-012-0344-z
Mezösi G, Meyer BC, Loibl W, Aubrecht C, Csorba P, Bata T (2012) Assessment of regional climate change impacts on Hungarian landscapes. Reg Environ Change. doi:10.1007/s10113-0120326-1

Rannow S (2013) Climate-adapted conservation: how to identify robust strategies for the management of reindeer in Hardangervidda National Park (Norway). Reg Environ Change. doi: 10.1007/s10113-013-0449-Z

Saathoff W, von Haaren C, Dechow R, Lovett A (2012). Farm-level assessment of $\mathrm{CO}_{2}$ and $\mathrm{N}_{2} \mathrm{O}$ emissions in Lower Saxony and comparison of implementation potentials for mitigation measures in Germany and England. Reg Environ Change. doi: 10.1007/s10113-012-0364-8

Tao F, Zhang S, Zhang Z (2012) Changes in rice disasters across China in recent decades and the meteorological and agronomic causes. Reg Environ Change. doi:10.1007/s10113-012-0357-7 